\title{
EVALUATION OF VERTICAL REFRACTIVITY Profile OVER Microwave LiNK IN MOWE, NigERIA
}

\author{
Sanyaolu Modupe Eunice \\ Department of Physical Sciences, Redeemers University, Ede, Osun State, Nigeria.
}

\begin{abstract}
The radio refractive index structure of the lower section of the atmospheric boundary layer is critical in the planning and construction of microwave communication connections. This study analyses the refractivity profile carried out in Mowe $\left(6.8085^{\circ} \mathrm{N}, 3.4367^{\circ}\right.$ E) South - Western Nigeria. Ground measurements of air pressure, temperature, and relative humidity used in this investigation were collected from the rain gauge of the Tropospheric Observatory Data Acquisition Network (TRODAN). The radio refractivity, associated refractivity gradient and climatic factor were computed using data from January 2012 to December 2013. The vertical distributions of radio refractivity were then calculated using these parameters. Seasonal fluctuations in refractivity are visible over the location, with high values in the wet season and low values in the dry season. The findings also suggest that propagation circumstances fluctuate in frequency, with sub-refractive situations being most common between April and September. This is an indication that microwave link in Mowe will suffer higher signal loss during wet season, while the loss may be mild during the dry season. The refractivity values in this study are expected to aid in determining the necessary mitigation to be put in place to reduce loss of signal in Mowe.
\end{abstract}

\section{KEYWORDS}

Temperature, Relative Humidity, Refractivity, refractivity gradient,

\section{INTRODUCTION}

The troposphere has been observed to be the lowest layer of the atmosphere, it has an extension of roughly 10 kilometers height from the earth's surface at mid-latitudes, having 6 kilometers at the poles, and up to 18 kilometers at the equator. These properties tend to adversely affect radio frequencies above $30 \mathrm{MHz}$ [1]- [3]. The bending of electromagnetic waves caused by changes in refractive index (density) in the atmosphere is known as refraction. It causes the multipath phenomenon, which causes receiver oscillations and delay dispersion, lowering link quality [4]. The troposphere's complexity is increased by atmospheric meteorological characteristics such as relative humidity, temperature, pressure, and water vapor density, which have a substantial impact on microwave transmission above $30 \mathrm{MHz}$ [5]. They interact in a variety of ways in the tropics, particularly along the coast, to change the radio refractivity gradient and propagation of radio waves [6]- [7]. Different activities arising from these meteorological and hydro meteorological elements have been key factors affecting radio propagation in Nigeria. It is worth mentioning that as the height above sea level varies; the atmosphere's refractivity will change as well, affecting radio transmissions. The ability to develop dependable and efficient radio communication (terrestrial and satellite) systems requires a thorough understanding of refractivity [8]-[10]. The troposphere's refractive index is therefore a critical element to consider when estimating the performance of terrestrial radio communications in a particular location. 
International Journal Of Microwave Engineering (JMICRO) Vol.6, No.1/2/3/4, October 2021

Several studies on radio refractivity have been conducted in some locations in Nigeria, some of these studies include the following: [11]-[19].

This study aims at evaluating the vertical refractivity profile over Mowe in other to plan for a better Quality of service (QoS) in this region of Nigeria.

\section{BACKGROUND}

Variations in the refractive index of the troposphere's air determine radio-wave propagation. The refractive index of air is measured by a quantity called the radio refractivity $\mathrm{N}$, which is related to refractive index, $\mathrm{n}$ as it is very close to unity (approximately 1.0003) [20]:

$$
n=1+N \times 10^{6}
$$

$\mathrm{N}$ is expressed as:

$$
N=77.6+\frac{p}{T}+3.73 \times 10^{5} \frac{e}{T^{2}}
$$

$\mathrm{p}$ is the air pressure ( $\mathrm{hPa}), \mathrm{T}$ is the absolute temperature in Kelvin. and e is the water vapour Water vapour e is expressed as

$$
\begin{aligned}
e & =\frac{\mathrm{e}_{\mathrm{s}}}{100} \\
\mathrm{e}_{\mathrm{s}} & =6.11 \exp \frac{17.502 t}{T+240.97}
\end{aligned}
$$

In general, $\mathrm{P}$ and e fall rapidly with height, whereas $\mathrm{T}$ decreases more slowly [21]. In midlatitude and temperate regions, horizontal variation of refractive index is often minimal in the lower troposphere compared to large-scale vertical variation, which has a median gradient of roughly $40 \mathrm{~N} / \mathrm{km}$ near the surface [22]. Local or mesoscale meteorological influences, especially in the tropics, can cause large variances [23]. Because of the enormous change in climatic conditions from the semi-arid region in the far north to the coastal region in the far south, this horizontal variation in refractive index is very large over Nigeria.

\section{Methods}

The study area for this research is Mowe, Ogun State, Nigeria. The research locations lie between Latitude $6.8085^{\circ} \mathrm{N}$ and longitude $3.4367^{\circ} \mathrm{E}$. The meteorological data used in this research work were obtained from the archives of Tropospheric Data Acquisition Network (TRODAN) domiciled in the Department of Physical Sciences at the Redeemer's University campus in Mowe, Ogun State, Nigeria.

$$
\begin{aligned}
& N=\mathrm{N}_{\text {dry }}+\mathrm{N}_{\text {wet }}=77.6+\frac{p}{T}+3.73 \times 10^{5} \frac{e}{T^{2}} \\
& \text { Refractivity gradient }(-d N)=\frac{d N}{d h}
\end{aligned}
$$

The measurement height is taken to be 100 meters from the ground. Hence these parameters are substituted to calculate the geoclimatic factor $(\mathrm{K})$ in equation (7) 
International Journal Of Microwave Engineering (JMICRO) Vol.6, No.1/2/3/4, October 2021

$$
K=\frac{1}{1+0.006371(-d N)}
$$

\section{RESUltS AND DiscuSSION}

A sub refraction condition occurs when the radio beam traveling across the connection is refracted upward, causing the portion of the wave front received at the far end to go closer to the ground than normal.Signal deterioration occurs as a result of this circumstance (attenuation).

The meteorological data were analysed on monthly basis as shown in Table 1.

Table 1: Monthly average meteorological data

\begin{tabular}{lll}
\hline MONTHS & RELATIVE HUMIDITY & TEMPERATURE $\left({ }^{0} \mathrm{c}\right)$ \\
\hline January & 65.21 & 30.5 \\
February & 60.41 & 29.3 \\
March & 78.53 & 28.4 \\
April & 80.60 & 28.1 \\
May & 81.50 & 28.6 \\
June & 90.61 & 26.1 \\
July & 88.12 & 24.2 \\
August & 92.44 & 27.5 \\
September & 87.63 & 28.6 \\
October & 70.51 & 29.0 \\
November & 70.32 & 29.9 \\
December & 62.10 & 30.0 \\
\hline
\end{tabular}

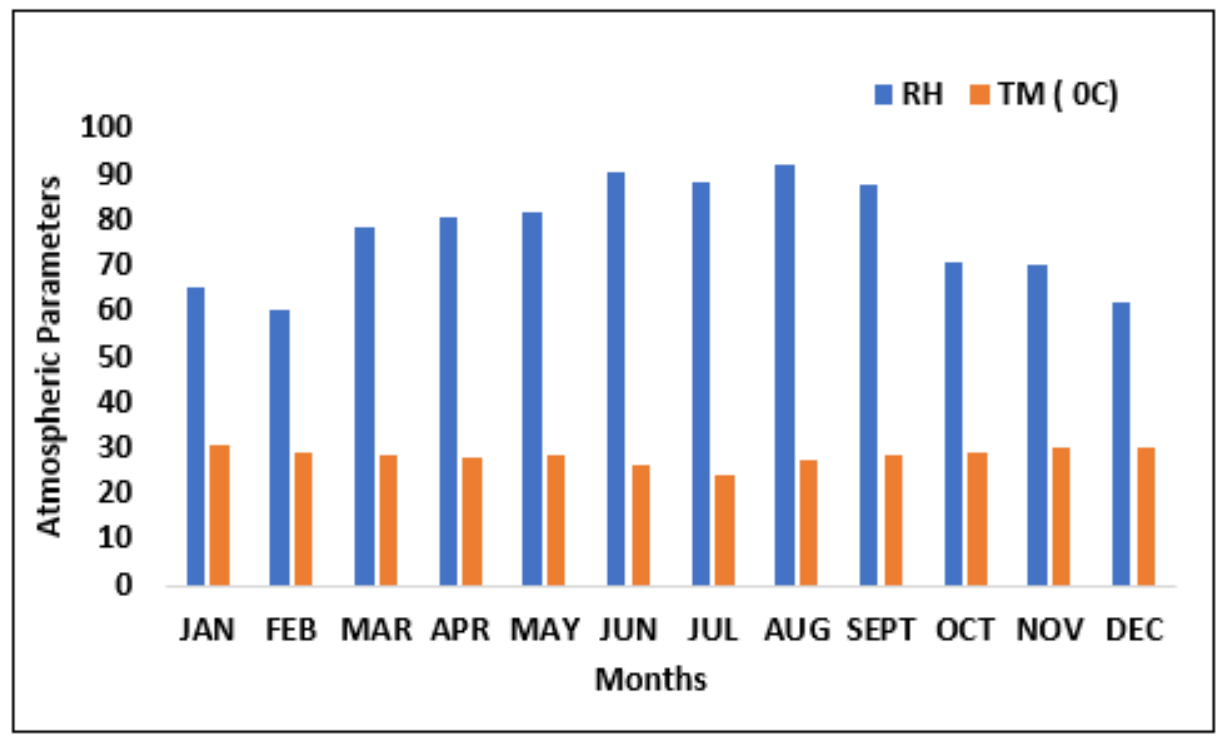

Figure 1: MonthlyDistribution of Relative Humidity and Temperature during observation Period

The results as shown in Table 1 and Figure 1 reveal the meteorological data of both temperature and relative humidity during the observation period. It is observed that the higher temperature corresponds to reduction in the relative humidity $(\mathrm{RH})$. The $\mathrm{RH}$ was seen to rise from March down to September. This could be the closeness of Mowe to Lagos which is in the coastline in Nigeria. 
International Journal Of Microwave Engineering (JMICRO) Vol.6, No.1/2/3/4, October 2021

Table 2: Monthly variations of Refractivity, refractivity gradient and the K factor

\begin{tabular}{l|l|l|l}
\hline MONTHS & REFRACTIVITY & $\begin{array}{l}\text { REFRACTIVITY } \\
\text { GRADIENT }\end{array}$ & K FACTOR \\
\hline January & 65.21 & 4.13 & 0.86 \\
February & 60.41 & 3.15 & 0.92 \\
March & 78.53 & 4.53 & 0.91 \\
April & 80.60 & 4.21 & 0.84 \\
May & 81.50 & 4.32 & 0.88 \\
June & 90.61 & 4.11 & 0.91 \\
July & 88.12 & 4.14 & 0.89 \\
August & 92.44 & 4.01 & 0.91 \\
September & 87.63 & 4.28 & 0.87 \\
October & 70.51 & 4.01 & 0.88 \\
November & 70.32 & 3.28 & 0.92 \\
December & 62.10 & 3.00 & 0.99 \\
\hline
\end{tabular}

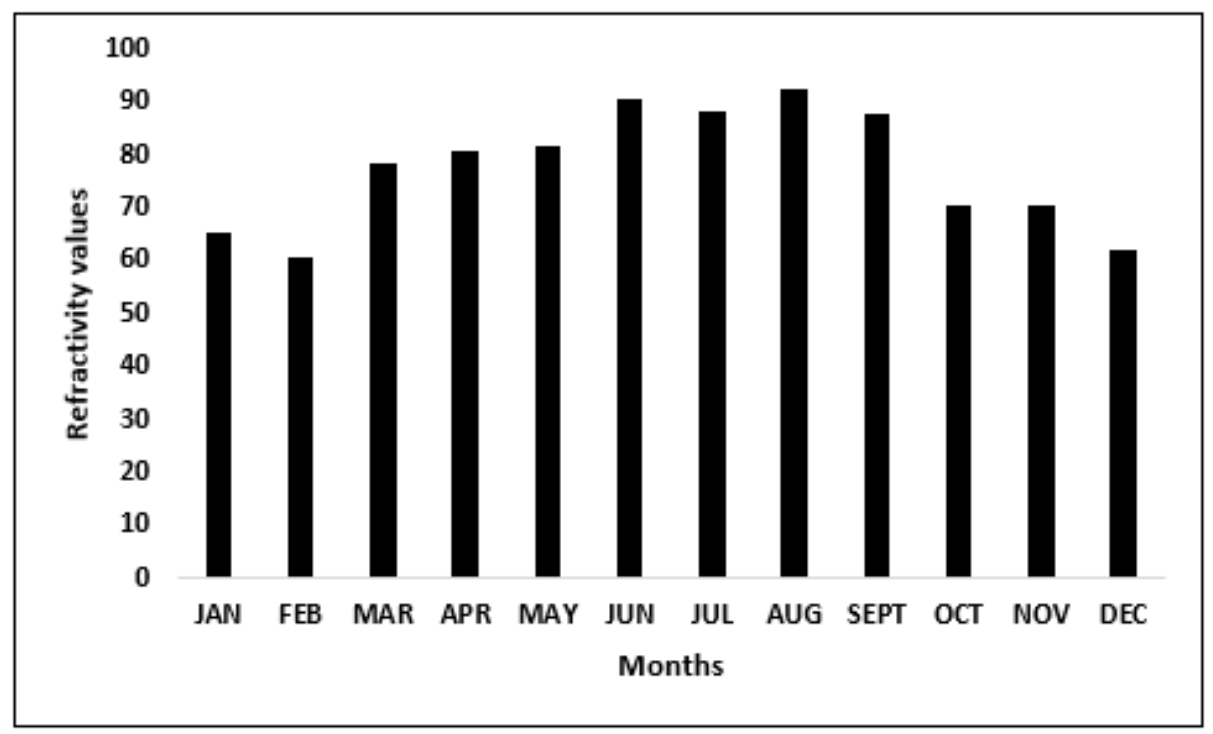

Figure 2: Monthly variations of Refractivity

Using equation (1)-(5) the surface refractivity was calculated and plotted as shown in Figure2. The result shows that refractivity is highest in August, followed by June with values of 92.44 and 90.61 respectively. It is also obvious that the higher values of the refractivity run from March to September. End of September and early October is usually the time when dry season sets in, in Mowe, the values at this time are seen to decrease till February. 
International Journal Of Microwave Engineering (JMICRO) Vol.6, No.1/2/3/4, October 2021

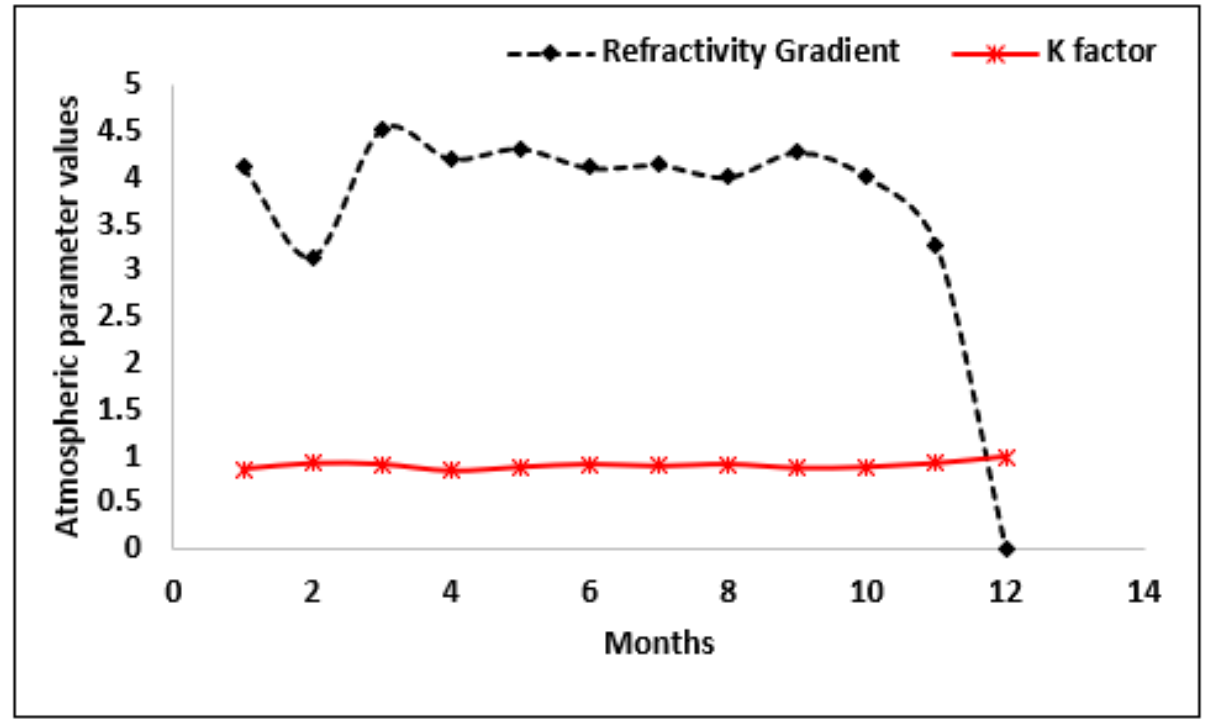

Figure 3: Monthly distribution of Refractivity gradient and the Geoclimatic (K) factor

Table 2 and figure 3 shows that the refractivity gradient is between 3.00 and 4.53 units throughout the year, and the earth radius factor is between 0.84 and 0.99. As a result, the link's refractive gradient is more than zero, whereas the earth radius factor is less than one. This is referred to as sub-refraction.

Table 2 also shows that the refractivity gradient is greatest in March and lowest in November, which definitely result to attenuation. As a result, signal coverage on the Mowe digital microwave link is predicted to deteriorate significantly in from March, with good reception more likely from November to February, when there will be clear weather.

\section{Conclusion}

The results of this investigation of radio refractivity on the microwave link in Mowe allow us to draw the conclusions that the effective earth radius factor was calculated to range between 0.84 and 0.99 . This allows one to deduce that the link has sub refraction.

For the period of two years, the refractivity gradient varies fairly over the year, with the lowest value in December and the highest value in August. Finally, the goal of this research is to create a database that may be used to impairment in on microwave communication links in this region of Nigeria.

\section{ACKNOWLEDGEMENTS}

I would like to thank everyone for their support on this study.

\section{REFERENCES}

[1] Hall, M. P. M. (1979). "Effects of the Troposphere on Radio Communication", Institute of Electrical Engineers.

[2] Isaakidis, A.S \&Xenos, D. (2004). "Ten years analysis of tropospheric refractivity variations", Annals of Geophysics Vol 47, pp 1-6. 
International Journal Of Microwave Engineering (JMICRO) Vol.6, No.1/2/3/4, October 2021

[3] Lear, M.W. (1980). “Computing atmospheric scale height for refraction corrections". (NASA) mission planning and analysis division Lyndon B Johnson space center.

[4] Zhang, Y. P., Hwang, Y., \& Ching, P. C. (1998). "Wide-band UHF radio propagation characteristics in a tunnel environment. Wireless Personal Communications”, 8, 291-299.

[5] Ojo, J.S.Adelakun, A.O.\&Edward, O.V. (2019) "Comparative study on Radio Refractivity Gradient in the troposphere using Chaotic Quantifiers,"Heliyon, 5(8), e02083-. doi:10.1016/j.heliyon.2019.e02083

[6] Goldhirsh, J. \& Dockery, D. (2005). "Propagation of radio waves in the atmosphere", John Hopkins University Whiting School of Engineering and Applied Science, unpublished Materials, Baltimore

[7] S. Zheng \& F. Han-Xian,(2013). " Monitoring of ducting by using a ground-based gps receiver", Chin. Phys. B 22 (2) 1-5.

[8] Tamosiunaite, M., et al., (2010) "Prediction of electromagnetic waves attenuation due to rain in the localities ofLithuania",Electronics and Electrical Engineering 9 (105), 9-12.

[9] Ojo Olalekan Lawrence, Ajewole Moses Oludare, Adediji Adekunle Titus, \&Ojo Joseph Sunday (2014). "Microwave Anomalous Propagation Conditions in the First 100-m Altitude in a Tropical Location", Journal of Microwave Power and Electromagnetic Energy, 48 (2), 2014, pp. 131-137

[10] Willoughby, A. A., Aro T. O. \& Owolabi, I. E. (2002). "Seasonal variations of radio refractivity gradients in Nigeria", Journal of Atmospheric and Solar-Terrestrial Physics, Vol. 64, pp 417-425.

[11] Kolawole, L. B. (1983) "Statistics of radio refractivity and atmospheric attenuation in tropical climates," Proceedings of the URSI Commission F Symposium, 69-75, Belgium,.

[12] Oyinloye, J. O.(1987) "The troposphere in tropical and sub-tropical latitudes," Handbook on Radio Propagation for Tropical and Sub-Tropical Countries, 77-79, URSICommittee on Developing Countries,.

[13] Oyedum, O. D. (2008). "Climatic and Seasonal Variations of Effective Earth Radius Factor and Scale Height in Three Meteorological Stations in West Africa”, Nigerian Journal of Physics, vol. 20, pp. $102-111$.

[14] Falodun, S. E. \& M. O. Ajewole, (2006) "Radio refractive index in the lowest $100 \mathrm{~m}$ layer of the troposphere in Akure, South Western Nigeria", Journal of Atmospheric and Solar-Terrestrial Physics, Vol. 68, 236-243,

[15] Adediji A. T., Mahamod I. \& Mandeep J. S. (2014). "Performance Analysis of Microwace Radio Refractivity on Radio Field Strength and Radio Horizon Distance over Akure, Nigeria". Wireless Personal Communications. Vol. 79, pp. 1893 - 1909.

[16] Falodun, S. E. \& Okeke, P. N. (2012). Radiowave Propagation Measurements in Nigeria (Preliminary Reports). Theoretical and Applied Climatology, pp 127 - 135 [7]

[17] Fuwape, I. A. \&Ogunjo, S.T. (2016)“Quantification of scaling exponents and dynamical complexity of microwave refractivity in a tropical climate," Journal of Atmospheric and Solar-Terrestrial Physics, vol. 150, pp. 61-68

[18] Adeyemi B. \& T. O. Aro (2004) "Variation in Surface Water Vapour Density Over Four Nigerian Stations". Nigeria Journal of Pure and Applied Physics, Vol. 3. No 1, pp 38-44

[19] Adediji, A. T, Mahamod Ismail and Mandeep J.S. (2013)“Incidences of Anomalous Propagation of Microwave Radio Signals Over Akure, Nigeria". Proceeding of the 2013 IEEE International Conference on Space Science and Communication (IconSpace), pp 102-105

[20] ITU-R, The Refractive Index: Its Formula and Refractivity Data, 453-9, 2003.

[21] ITU-R, "The radio refractive index: Its formula and refractivity data," 453-459, 2003.

[22] Bean, B. R., C. A. Cahoon, C. A. Samson, and G. D. Thayer, A World Atlas of Radio Refractivity, Monograph, No. 1, Environmental Sciences Services Administration, U.S. Government Printing Office, Washington D.C., 1966.

[23] Bean, B. R. \&Cahoon, B. A. (1961) "Correlation of monthly median transmission loss and refractive index profile characteristics,” J. Res. N.B.S., Vol. 65, No. 1, 67-74, 